\title{
DIVERSIDADE GENÉTICA DE PITAYAS NATIVAS DO CERRADO COM BASE EM MARCADORES RAPD ${ }^{1}$
}

\author{
KEIZE PEREIRA JUNQUEIRA², FÁBIO GELAPE FALEIRO 3 , \\ NILTON TADEU VILELA JUNQUEIRA ${ }^{3}$, GRACIELE BELLON ${ }^{3}$, \\ CRISTIANE ANDRÉA DE LIMA ${ }^{3}$, LUCIANA SOBRAL DE SOUZA
}

RESUMO - As pitayas do Cerrado vegetam naturalmente sobre maciços rochosos de arenito ou quartzito, troncos de árvores e em solos arenosos de campos rupestres de Minas Gerais, Bahia, Goiás, Distrito Federal, Tocantins, Rio de Janeiro e Bahia, havendo fortes evidências de que a região central do Brasil seja o maior centro de dispersão das pitayas, tendo em vista a grande diversidade fenotípica observada em acessos coletados. Objetivou-se realizar o estudo da diversidade genética de 13 acessos de pitayas mantidos na coleção de germoplasma da Embrapa Cerrados por meio de marcadores moleculares RAPD (Random Amplified Polymorphic DNA). O DNA genômico de cada acesso foi extraído, e quatorze iniciadores decâmeros foram utilizados para a obtenção de marcadores moleculares RAPD, que foram convertidos em matriz de dados binários, a partir da qual foram estimadas as distâncias genéticas entre os acessos com base no complemento do coeficiente de similaridade de Nei e Li (1979) e realizadas análises de agrupamento e de dispersão gráfica. Foram obtidos 162 marcadores RAPD, perfazendo uma média de 11,57 marcadores por primer. Do total de marcadores, 154 (95,06\%) foram polimórficos. As distâncias genéticas variaram entre 0,088 e 0,848, sendo que os maiores valores observados se referem a distância entre o acesso de Unaí-MG e o acesso Seleção Embrapa Cerrados. O acesso que mais se diferenciou dos demais foi "Unaí-MG”, que apresentou uma distância genética média de 0,675 em relação aos demais acessos. A alta distância genética verificada é devido ao fato de os referidos acessos não pertencerem à mesma espécie. Os agrupamentos dos acessos de pitaya pouco se relacionaram com a origem geográfica dos mesmos. A grande diversidade genética das pitayas encontradas no Cerrado permite incluir esse Bioma no centro de diversidade e abre boas perspectivas para maiores estudos acerca do potencial dessa frutífera.

Termos para indexação: marcadores moleculares, Cactaceae, fruta exótica.origem geográfica, dragon fruit.

\section{GENETIC DIVERSITY OF NATIVE PITAYA FROM BRAZILIAN SAVANNAS WITH BASIS ON RAPD MARKERS}

\begin{abstract}
Brazilian savanna pitayas naturally vegetate on solid rocky sandstone or quartzite, tree trunks and on rocky fields sand soils at Minas Gerais, Goiás, Distrito Federal, Tocantins, Rio de Janeiro and Bahia, with strong evidences that Brazil central region is the biggest pitayas dispersion center, because of the wide phenotypic diversity observed in collected accesses. The objective was to realize genetic diversity study of 13 pitaya accesses maintained at Embrapa Cerrados germoplasm collection through RAPD (Random Amplified Polymorphic DNA) molecular markers. Each access genomic DNA were extracted and fourteen decamer initiators were used to obtain RAPD molecular markers, that were converted in a binary data matrix, from where we estimate genetic distances between accesses and realize grouping and graphic dispersion analysis. 162 RAPD markers were obtained, making 11,57 markers medium per primer. From all the markers, 154 $(95,06 \%)$ were polymorphic. Genetic distances varied within 0,088 and 0,848 , the biggest values observed refer to distance between Unaí, MG access and Seleção Embrapa Cerrados access. The most different access was "Unaí, MG", that showed 0,675 of genetic distance average in relation to others accessions. The high genetic distance verified is due to the fact that the referred accesses do not belong to the same species. Pitaya accesses groups had little relation to their geographic origin. The genetic diversity found at the Brazilian savannas allows including this biome at pitaya species diversity center, showing good perspectives to studies about this fruit potential.
\end{abstract}

Index terms: molecular markers, Cactaceae, exotic fruit.

${ }^{1}$ (Trabalho 184-09). Recebido em: 10-08-2009. Aceito para publicação: 02-03-2010. Apoio financeiro: CAPES e Embrapa Cerrados.

${ }^{2}$ Embrapa Transferência de Tecnologia, Embrapa Sede, Parque Estação Biológica - PqEB s/nº 70770-901, Brasília, DF. Email: keize.junqueira@embrapa.br

${ }^{3}$ Embrapa Cerrados, BR 020, Km 18, Caixa Postal 08223, 73010-970 Planaltina-DF. E-mail: ffaleiro@cpac.embrapa.br, junqueir@cpac.embrapa.br. 


\section{INTRODUÇÃO}

Pertencentes à família Cactacea, as pitayas vêm destacando-se no mercado de frutas exóticas. Há várias espécies denominadas "pitayas", dentre as quais podem ser citadas Hylocereus undatus (pitaya-vermelha-de-polpa-branca), H. costaricensis (pitaya-vermelha-de-polpa-vermelha), Selenicereus megalanthus (pitaya-amarela) e S. setaceus (pitayado-cerrado). Há também outras espécies de ocorrência em áreas de Cerrado.

A espécie mais cultivada atualmente é a pitayavermelha-de-polpa-branca. Colômbia e México são os principais produtores mundiais (ANDRADE et al., 2005). Os frutos são bastante atrativos, de coloração vermelha e polpa esbranquiçada, com numerosas sementes pretas.

As pitayas do Cerrado vegetam naturalmente sobre maciços rochosos de arenito ou quartzito, troncos de árvores e em solos arenosos de campos rupestres dos Cerrados de Minas Gerais, Bahia, Goiás, Distrito Federal e Tocantins. Há relatos de sua ocorrência também em áreas de restinga na Bahia e Rio de Janeiro (JUNQUEIRA et al., 2002). Apesar do baixo peso, as pitayas do Cerrado apresentam alto teor de sólidos solúveis, superior ao da pitayavermelha, o que lhes confere o sabor mais adocicado.

Há fortes evidências de que a região central do Brasil seja o maior centro de dispersão das pitayas, tendo em vista a grande diversidade fenotípica observada em acessos coletados em Goiás, Minas Gerais, Bahia, Mato Grosso e Tocantins. Para subsidiar e confirmar tais evidências, neste trabalho, objetivou-se realizar o estudo da diversidade genética de 13 acessos de pitayas mantidos na coleção de germoplasma da Embrapa Cerrados por meio de marcadores moleculares RAPD (Random Amplified Polymorphic DNA).

\section{MATERIAL E MÉTODOS}

O trabalho foi realizado no Laboratório de Genética e Biologia Molecular da Embrapa Cerrados. Foram analisados 13 acessos de pitayas nativas do Cerrado. Um acesso de pitaya comercial (Hylocereus undatus, Seleção Embrapa Cerrados) foi utilizado como outgroup (Tabela 1). Cladódios em estágio inicial de maturação foram coletados, e o DNA genômico extraído, utilizando-se do método do CTAB, com algumas modificações e otimizações feitas por Faleiro et al. (2003).

Amostras de DNA de cada material genético foram amplificadas para a obtenção de marcadores RAPD. As reações de amplificação foram feitas em um volume total de $13 \mu \mathrm{L}$, contendo Tris- $\mathrm{HCl} 10 \mathrm{mM}$ ( $\mathrm{pH} 8,3$ ), $\mathrm{KCl} 50 \mathrm{mM}, \mathrm{MgCl}_{2} 3 \mathrm{mM}, 100 \mu \mathrm{M}$ de cada um dos desoxirribonucleotídios (dATP, dTTP, dGTP e dCTP), $0,4 \mu \mathrm{M}$ de um primer (Operon Technologies Inc., Alameda, CA, EUA), uma unidade da enzima Taq polimerase e, aproximadamente, $15 \mathrm{ng}$ de DNA. Foram utilizados 14 primers decâmeros: OPD (01; 02; 05 e 12), OPE (02; 11 e 16), OPF (08 e 14), OPG (05 e 18) e OPH $(04,13$ e 15).

As amplificações foram efetuadas em termociclador programado para 40 ciclos, cada um constituído pela seguinte sequência: 15 segundos a $94^{\circ} \mathrm{C}, 30$ segundos a $35^{\circ} \mathrm{C}$ e 90 segundos a $72^{\circ} \mathrm{C}$. Após os 40 ciclos, foi feita uma etapa de extensão final de seis minutos a $72^{\circ} \mathrm{C}$ e, finalmente, a temperatura foi reduzida para $4{ }^{\circ} \mathrm{C}$. Após a amplificação, foram adicionados, a cada amostra, $3 \mu \mathrm{L}$ de uma mistura de azul de bromofenol (0,25\%) e glicerol (60\%), em água. Essas amostras foram aplicadas em gel de agarose $(1,2 \%)$, corado com brometo de etídio, submerso em tampão TBE (Tris-Borato $90 \mathrm{mM}$, EDTA $1 \mathrm{mM}$ ). A separação eletroforética foi de, aproximadamente, quatro horas, a 90 volts. Ao término da corrida, os géis foram fotografados sob luz ultravioleta.

Os marcadores RAPD gerados foram convertidos em matriz de dados binários, a partir da qual foram estimadas as distâncias genéticas entre os diferentes acessos, com base no complemento do coeficiente de similaridade de Nei e Li (1979), utilizando-se do Programa Genes (CRUZ, 1997). A matriz de distâncias genéticas foi utilizada para realizar análises de agrupamento por meio de dendrograma, utilizando-se do método do UPGMA (Unweighted pair-group arithmetic average) como critério de agrupamento, e a dispersão gráfica, baseada em escalas multidimensionais, usando o método das coordenadas principais, com auxílio do Programa SAS (SAS Institute Inc., 1989) e Statistica (Statsoft Inc., 1999 ).

\section{RESULTADOS E DISCUSSÃO}

Os 14 primers decâmeros geraram um total de 162 marcadores RAPD, perfazendo uma média de 11,57 marcadores por primer. Do total de marcadores, $154(95,06 \%)$ foram polimórficos. A alta porcentagem de marcadores polimórficos evidencia a presença de alta diversidade genética nas pitayas nativas do Cerrado. Marcadores RAPD têm sido utilizados com sucesso e revelado elevado polimorfismo entre acessos de diferentes espécies, incluindo espécies nativas do Cerrado (SALLA et al., 2002; BIANCHI et al., 2003, JUNQUEIRA et 
al., 2006; BELLON et al., 2007).

A diversidade de locais de coleta implica diferentes capacidades adaptativas dos acessos analisados, o que é de extremo interesse para programas de melhoramento genético, visando à obtenção de variedades adaptadas a diferentes regiões ou sistemas agrícolas do País (GANGA et al., 2004). Assim, a avaliação da divergência genética possibilita selecionar combinações com maiores possibilidades de complementação gênica e recuperação de genótipos superiores nas gerações segregantes (GANGA et al., 2004).

As distâncias genéticas entre os 13 acessos de pitaya variaram entre 0,088 e 0,848 (Tabela 2). Os maiores valores observados referem-se a distância entre o acesso de Unaí-MG (pitaya oval sem espinhos, Harrisia sp.) e o acesso Seleção Embrapa Cerrados (Hylocereus undatus). $\mathrm{O}$ acesso que mais se diferenciou dos demais foi o procedente de UnaíMG (pitaya oval sem espinhos, Harrisia sp.), que apresentou distância genética média de 0,675 em relação aos demais acessos. A alta distância genética verificada é devido ao fato de os referidos acessos não pertencerem à mesma espécie.

A partir da análise de agrupamento realizada com base nas distâncias genéticas, subdividiramse os 13 acessos em, pelo menos, 7 grupos de similaridade genética, sendo 2 grupos dentro da espécie Selenicereus setaceus, 2 grupos pertencentes à espécie Hylocereus undatus, 1 grupo dentro de Selenicereus megalanthus e 2 grupos com taxonomia desconhecida (Figura 1). Observou-se que os agrupamentos dos acessos de pitaya pouco se relacionaram com a origem geográfica dos mesmos. As distâncias entre os acessos e a distribuição dos mesmos nos grupos de similaridade podem ser também observadas no gráfico de dispersão (Figura 2). Nessa análise de dispersão, evidencia-se o agrupamento dos acessos CPAC PY-11 e CPAC PY12 , oriundos de Unaí e a alta diversidade genética desses acessos em relação aos demais. Esses acessos comportaram-se como outgroups.

A ausência de correlação entre grau de similaridade genética e procedência de acessos também foi obtida por Salla et al. (2002), que estudaram a variabilidade genética de 24 acessos de aceroleiras (Malpighia emarginata) por RAPD.

No presente trabalho, o maior grupo foi formado por 4 acessos, todos pertencentes à espécie Selenicereus setaceus, procedentes do Distrito Federal, Goiás e Minas Gerais. Dentro deste grupo, pode-se verificar maior similaridade entre os acessos "Itumirim-MG" e "Cruzília-MG" $(0,118)$. Considerando-se os dois grupos contendo acessos de Selenicereus setaceus, as distâncias genéticas variaram de 0,118 a 0,407 . Os altos valores observados dentro do mesmo grupo refletem significativa variabilidade intraespecífica.

A grande diversidade genética encontrada no Cerrado permite incluir esse Bioma no centro de diversidade das espécies de pitaya, abrindo boas perspectivas para maiores estudos acerca do potencial dessas espécies como frutíferas comerciais. Além disso, segundo Ganga et al. (2004), a identificação de genitores com alta divergência tem sido o objetivo de muitos trabalhos de melhoramento para que, realizada a hibridação, ocorra uma segregação tal na progênie que aumente as possibilidades de ocorrência de genótipos superiores com constituições ajustadas ao ambiente. Entretanto, para validar esta abordagem, devem-se aliar as informações obtidas por meio de técnicas moleculares ao desempenho desses materiais em condições de cultivo, orientando programas de melhoramento. Assim, a caracterização morfoagronômica de germoplasma torna-se necessária, visando a assegurar informações sobre fontes de genes para utilização futura que, além de prevenirem a perda desses recursos, também podem ser de grande importância para o desenvolvimento da cultura da pitaya no Brasil. 
TABELA 1 - Acessos de pitaya analisados, com os respectivos locais de coleta e códigos do Banco de Germoplasma da Embrapa Cerrados.

\begin{tabular}{cccc}
\hline Número & Procedência & Espécie & Código \\
\hline 1 & Barbacena-MG & Selenicereus setaceus & CPAC PY-02 \\
2 & Unaí-MG (Pitaya com espinho) & Selenicereus setaceus & CPAC PY-03 \\
3 & Tiradentes-MG & Hylocereus undatus & CPAC PY-04 \\
4 & Lavras-MG & Hylocereus undatus & CPAC PY-05 \\
5 & Itumirim-MG & Selenicereus setaceus & CPAC PY-06 \\
6 & Cruzília-MG & Selenicereus setaceus & CPAC PY-07 \\
7 & Cristalina-GO & Selenicereus setaceus & CPAC PY-08 \\
8 & Formosa-GO & Espécie não identificada & CPAC PY-09 \\
9 & São Bartolomeu-DF & Selenicereus setaceus & CPAC PY-10 \\
10 & Jalapão-TO & Selenicereus megalanthus & CPAC PY-11 \\
11 & Unaí-MG (Pitaya longa sem espinho) & Harrisia sp. & CPAC PY-12 \\
12 & Unaí-MG (Pitaya oval sem espinho) & Harrisia sp. & CPAC PY-13 \\
13 & Seleção, Embrapa Cerrados & Hylocereus undatus & CPAC PY-01 \\
\hline
\end{tabular}

TABELA 2 -Matriz de distâncias entre 13 acessos de Pitaya, calculadas com base no complemento do coeficiente de similaridade de Nei e Li, utilizando-se de 162 marcadores RAPD.

\begin{tabular}{|c|c|c|c|c|c|c|c|c|c|c|c|c|c|}
\hline $\mathbf{N}^{\mathbf{o}}$ & 1 & 2 & 3 & 4 & 5 & 6 & 7 & 8 & 9 & 10 & 11 & 12 & 13 \\
\hline 1 & 0,000 & 0,172 & 0,366 & 0,393 & 0,235 & 0,206 & 0,262 & 0,452 & 0,309 & 0,416 & 0,683 & 0,690 & 0,463 \\
\hline 2 & 0,172 & 0,000 & 0,340 & 0,367 & 0,290 & 0,318 & 0,358 & 0,438 & 0,407 & 0,397 & 0,689 & 0,692 & 0,649 \\
\hline 3 & 0,366 & 0,340 & 0,000 & 0,088 & 0,451 & 0,481 & 0,457 & 0,494 & 0,495 & 0,464 & 0,701 & 0,770 & 0,560 \\
\hline 4 & 0,393 & 0,367 & 0,088 & 0,000 & 0,465 & 0,475 & 0,449 & 0,478 & 0,486 & 0,520 & 0,710 & 0,761 & 0,737 \\
\hline 5 & 0,235 & 0,290 & 0,451 & 0,465 & 0,000 & 0,118 & 0,200 & 0,469 & 0,211 & 0,345 & 0,720 & 0,699 & 0,565 \\
\hline 6 & 0,206 & 0,318 & 0,481 & 0,475 & 0,118 & 0,000 & 0,119 & 0,459 & 0,150 & 0,318 & 0,662 & 0,707 & 0,519 \\
\hline 7 & 0,262 & 0,358 & 0,457 & 0,449 & 0,200 & 0,119 & 0,000 & 0,426 & 0,231 & 0,357 & 0,657 & 0,667 & 0,607 \\
\hline 8 & 0,452 & 0,438 & 0,494 & 0,478 & 0,469 & 0,459 & 0,426 & 0,000 & 0,414 & 0,415 & 0,726 & 0,758 & 0,552 \\
\hline 9 & 0,309 & 0,407 & 0,495 & 0,486 & 0,211 & 0,150 & 0,231 & 0,414 & 0,000 & 0,200 & 0,722 & 0,696 & 0,500 \\
\hline 10 & 0,416 & 0,397 & 0,464 & 0,520 & 0,345 & 0,318 & 0,357 & 0,415 & 0,200 & 0,000 & 0,672 & 0,639 & 0,391 \\
\hline 11 & 0,683 & 0,689 & 0,701 & 0,710 & 0,720 & 0,662 & 0,657 & 0,726 & 0,722 & 0,672 & 0,000 & 0,171 & 0,803 \\
\hline 12 & 0,690 & 0,692 & 0,770 & 0,761 & 0,699 & 0,707 & 0,667 & 0,758 & 0,696 & 0,639 & 0,171 & 0,000 & 0,848 \\
\hline 13 & 0,463 & 0,649 & 0,560 & 0,737 & 0,565 & 0,519 & 0,607 & 0,552 & 0,500 & 0,391 & 0,803 & 0,848 & 0,000 \\
\hline DGM & 0,387 & 0,426 & 0,472 & 0,494 & 0,397 & 0,378 & 0,399 & 0,507 & 0,402 & 0,428 & 0,660 & 0,675 & 0,600 \\
\hline
\end{tabular}

* O número do acesso é o mesmo da Tabela 1.

DGM - Distância genética média 


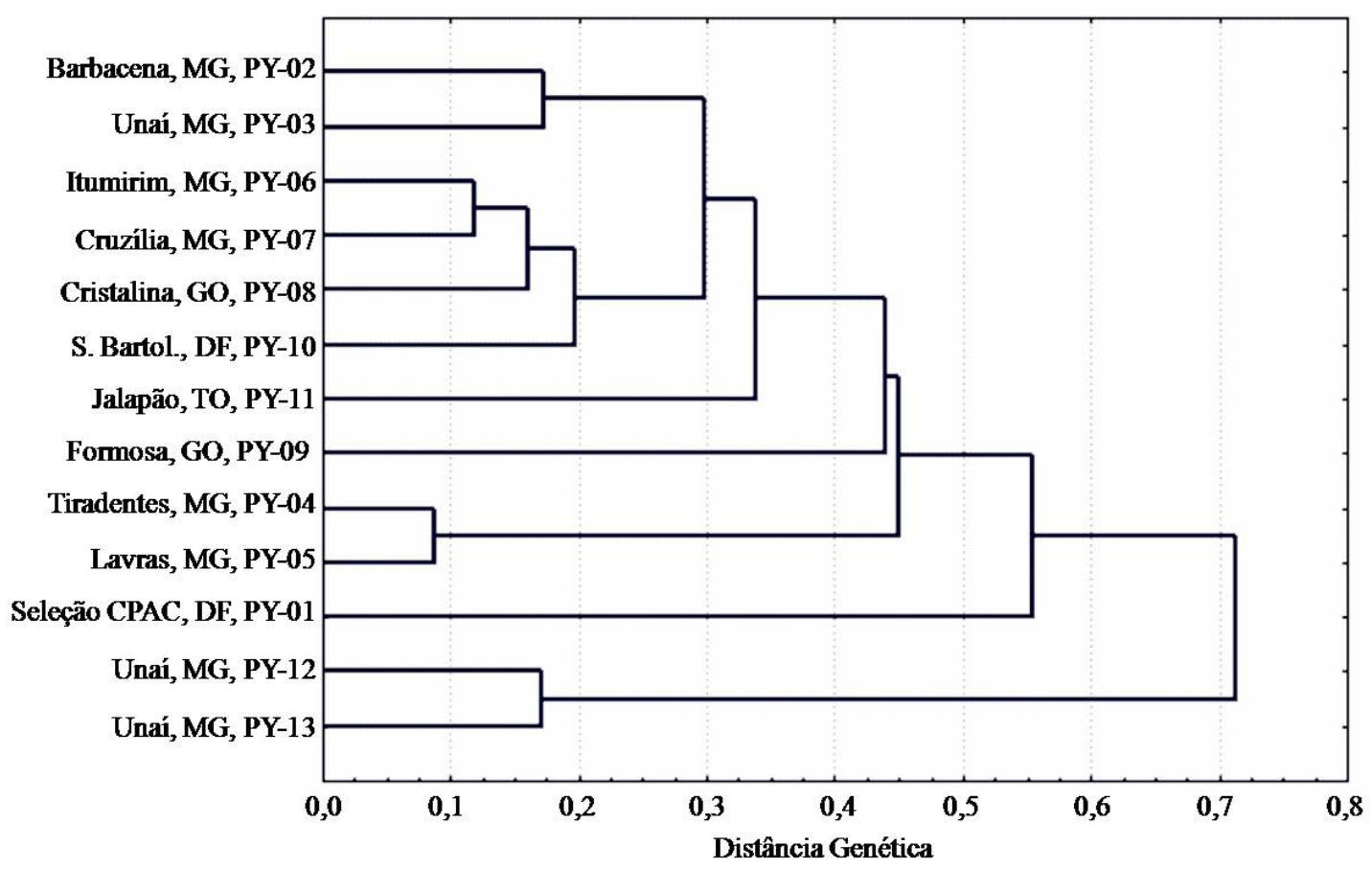

FIGURA 1 - Análise de agrupamento de 13 acessos de pitaya com base na matriz de distâncias genéticas calculadas, utilizando-se de 162 marcadores RAPD. O método do UPGMA foi utilizado como critério de agrupamento.

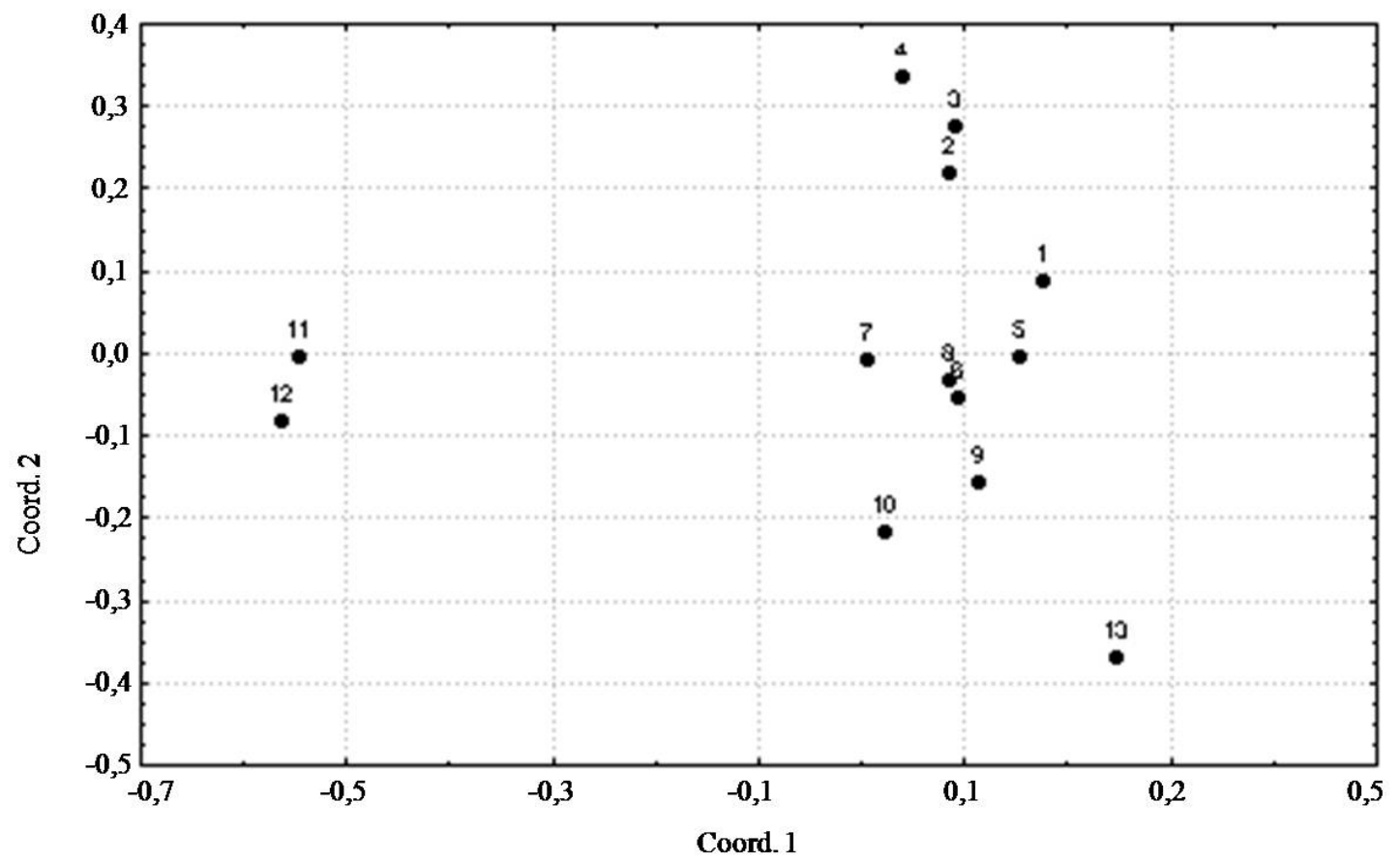

FIGURA 2 - Dispersão gráfica de 13 acessos de pitaya com base na matriz de distâncias genéticas calculadas, utilizando-se de 162 marcadores RAPD. Os números correspondem aos acessos da Tabela 1. 


\section{CONCLUSÃO}

Há grande diversidade genética entre os acessos de pitayas nativas do Cerrado, posicionando esse Bioma entre os centros de diversidade dessas espécies. Essa alta diversidade fornece subsídios para estudos envolvendo seleção de materiais com características agronômicas mais desejáveis e utilização desse germoplasma no melhoramento da pitaya comercial. Além disso, tal diversidade abre boas perspectivas para maiores estudos acerca do potencial desses acessos e espécies como frutíferas comerciais.

\section{REFERÊNCIAS}

ANDRADE, R.A.; OLIVEIRA, I.V.M.; MARTINS, A.B.G. Influência da condição e período de armazenamento na germinação de sementes de pitayavermelha. Revista Brasileira de Fruticultura, Jaboticabal, v.27, n.1, p. 168-170. 2005.

BIANCHI, V. J.; FACHINELLO, J. C.; SCHUCH, M. W. RAPDs na caracterização genético-molecular e no estudo da variabilidade genética de cultivares de ameixeira. Revista Brasileira de Fruticultura, Jaboticabal, v. 25, n. 2, p. 272-274. 2003.

BELLON, G.; FALEIRO, F.G.; JUNQUEIRA, K.P.; JUNQUEIRA, N.T.V.; SANTOS, E.C.; BRAGA, M.F.; GUIMARÃES, C.T. Variabilidade genética de acessos silvestres e comerciais de Passiflora edulis Sims. com base em marcadores RAPD. Revista Brasileira de Fruticultura, Jaboticabal, v.29, n.1, p. 124-127. 2007.

CRUZ, C.D. Programa genes: aplicativo computacional em genética e estatística. Viçosa: Editora UFV, 1997. 648p.

FALEIRO, F. G.; FALEIRO, A. S. G.; CORDEIRO, M. C. R.; KARIA, C. T. Metodologia para operacionalizar a extração de DNA de espécies nativas do cerrado. Planaltina: Embrapa Cerrados, 2003. 6 p. (Comunicado Técnico, 92).

GANGA, R. M. D.; RUGGIERO, C.; LEMOS, E. G. M.; GRILI, G. V. G.; GONÇALVES, M. M; CHAGAS, E. A.; WICKERT, E. Diversidade genética em maracujazeiro-amarelo utilizando marcadores moleculares fAFLP. Revista Brasileira de Fruticultura, Jaboticabal, v.6, n.3, p.494-498. 2004.
JUNQUEIRA, K.P. Características físico-químicas de frutos e variabilidade genética de Passiflora nitida Kunth. por meio de RAPD. 2006. $114 \mathrm{f}$. Dissertação (Mestrado) - Universidade Federal de Lavras, Lavras, 2006.

JUNQUEIRA, K.P.; JUNQUEIRA, N.T.V.; RAMOS, J.D.; PEREIRA, A.V. Informações preliminares sobre uma espécie de pitaya do Cerrado. Planaltina-DF: Embrapa Cerrados, 2002. 18p. (Documentos, 62).

NEI, M.; LI, W. H. Mathematical model for studying genetic variation in terms of restriction endonucleases. Proceedings of the National Academy of Science of the United States of America, Washington, v.76, n.10, p.5269-5273, 1979.

SALLA, M. F. S.; RUAS, C. F.; RUAS, P. M.; CARPENTIERI-PÍPOLO, V. Uso de marcadores moleculares na análise da variabilidade genética em acerola (Malpighia emarginata D. C.). Revista Brasileira de Fruticultura, Jaboticabal, v.24, n.1, p.15-22, 2002.

SAS INSTITUTE. SAS/STAT user's guide. Version 6. $4^{\text {th }}$ ed. North Caroline, 1989.

SAWAZAKI, H. E.; BARBOSA, W.; COLOMBO, C. A. Caracterização e identificação de cultivares e seleções de pereiras através de marcadores RAPD. Revista Brasileira de Fruticultura, Jaboticabal, v. 24, n. 2, p. 447-452. 2002.

STATSOFT. Statistica for Windows: computer program manual. Tulsa, 1999. 